\title{
A influência da oralidade na producuão escrita de estudantes do ensino fundamental: uma discussão sobre possiveis práticas pedagógicas voltadas para o desenvolvimento metassintático
}

The influence of orality in the written production of students in middle school: a discussion on possible pedagogical practices aiming at metasyntactic development

\author{
Adriana Tavares Maurício Lessa \\ Universidade Federal do Rio de Janeiro - UFRJ \\ Magda do Nascimento Rodrigues
}

Universidade Federal Rural do Rio de Janeiro - UFRRJ

DOI: https://doi.org/10.5902/2176148538819

\begin{abstract}
Resumo: Este artigo tem como objetivo geral caracterizar sintaticamente a influência da oralidade na produção escrita dos estudantes do Ensino Fundamental. Especificamente, buscamos ilustrar como determinadas marcas sintáticas de oralidade se manifestam e debater possíveis práticas pedagógicas para o desenvolvimento metassintático dos estudantes. Para tanto, exemplificamos as seguintes marcas sintáticas de oralidade na escrita de alunos do sétimo ano: apagamento de termos oracionais, reativação de itens lexicais, ordenamento sintático do tipo tópico-comentário, ocorrência de itens fáticos e não marcação da fronteira sintática. Apresentamos, ainda, um relato de experiência pedagógica com base em conversas metassintáticas.
\end{abstract}

Palavras-chave: Oralidade. Escrita. Sintaxe. Desenvolvimento metassintático.

\begin{abstract}
This article aims to characterize syntactically the influence of orality in the written production of students in Middle School. Specifically, we aim to illustrate how some main oral syntactic marks are exhibited and to debate possible pedagogical practices to students' metasyntactic development. In order to do so, we illustrate the following syntactic marks of orality in the written production of students of the 7th grade: omission of subsentential terms, reactivation of lexical itens, topic-commentary syntactic order, occurrence of phatic itens and the unmarkedness of syntactic boundaries.
\end{abstract}

Keywords: Orality. Writing. Syntax. Metasyntactic development. 


\section{Introdução}

A sintaxe do português brasileiro vem sendo objeto de inúmeras pesquisas linguísticas nas últimas décadas. A partir de sua caracterização sintática, a transição de paradigma sintático em relação ao português

Adriana europeu está empiricamente documentada. A consolidação dessa muTavares dança sintática marca um aprofundamento do "abismo" entre língua Maurício Lessa

Magda do Nascimento Rodrigues falada e língua escrita, no sentido proposto por Bagno (2009).

Pensando-se nos impactos que essas mudanças trouxeram para o processo de ensino-aprendizagem da prática social de escrita, a Sociolinguística forneceu valiosas contribuições acerca da importância do ensino de gramática numa perspectiva variacionista (cf. BAGNO, 2009; BORTONI-RICARDO et al., 2016; VIEIRA, 2017). No entanto, os materiais que caracterizam sintaticamente a língua, destinados aos professores, tendem a ter como foco determinado fenômeno linguístico a partir do continuum fala-escrita. Há trabalhos, por exemplo, explicitando a variação quanto à concordância de número; outros, quanto à coesão referencial. Logo, sua organização tem como foco o fenômeno linguístico, condizente com uma proposta de análise teórica dessa variação. Por fim, fica a cargo do professor a tarefa de reunir essas informações fragmentadas ao lidar com o texto produzido pelo aluno.

Diante desse quadro, constata-se uma lacuna na literatura no que tange a contribuições para professores de língua materna que tenham como foco a produção escrita do estudante. Sendo assim, o objetivo geral deste artigo é caracterizar sintaticamente a influência da oralidade na produção escrita dos estudantes. Como objetivos específicos, definimos: (a) ilustrar como as principais marcas sintáticas de oralidade se manifestam na produção escrita de estudantes de Ensino Fundamental e (b) debater possíveis práticas pedagógicas para o desenvolvimento metassintático dos estudantes.

Metodologicamente, investigar como o aluno cogniza seu processo de escrita é tomado como condição pressuposta para se pensar o ensino de gramática com vistas à potencialização das práticas de linguagem do estudante (cf. GERHARDT, 2017). Portanto, este artigo se propõe a inverter o foco de análise para a produção dos estudantes como abordagem metodológica que corrobora uma perspectiva cognitivista sobre as práticas de linguagem. 


\section{Sintaxe e escrita como processos cognitivos}

A sintaxe é definida, de acordo com Azeredo (1990), como o sistema capaz de permitir a criação e a interpretação de frases. Apesar de a língua apresentar um número limitado de elementos linguísticos - como sons e palavras - as possibilidades de combinação desses elementos são infinitas.

Ao se pensar a relação entre oralidade e escrituralidade, é fundamental que se reconheça que as regras de combinação sintática manifestam-se diferentemente em cada uma dessas modalidades. Pode-se afirmar, inclusive, que cada modalidade apresenta uma gramática específica, com possibilidades de organização sintática bastante diversas. Não se trata de estabelecer níveis de importância e de valorização entre elas, como se fez durante muito tempo, mas de compreender essas particularidades e perceber as possíveis interferências de uma modalidade sobre a outra.

A influência
da oralidade
na produção
escrita de
estudantes
do ensino
fundamental

465 naturalmente, pela fala. Os primeiros conhecimentos sintáticos com os quais os usuários de uma língua têm contato desenvolvem-se sem interferência instrucional significativa, a partir da convivência com outros falantes. Isso significa que a fala representa um sistema simbólico de primeira ordem, visto que sua aquisição se dá de forma natural, ainda na infância (BORTONI-RICARDO, GONDIM \& BENÍCIO, 2010). A mera exposição a essa modalidade garante à criança a possibilidade de se comunicar adequadamente dentro de seu grupo familiar e social.

Por outro lado, o sistema de escrita, instituição relativamente nova na história da humanidade, surge inicialmente como a tentativa de representação do fonema a partir de um grafema que o simbolizasse. A escrita exige o aprendizado institucionalizado pela escola, constituindo, assim, um sistema de segunda ordem (BORTONI-RICARDO, GONDIM \& BENÍCIO, 2010).

Tamanhas diferenças entre essas modalidades geram grandes desafios a professores e alunos, que se iniciam durante o processo de alfabetização, mas que não se encerram aí. A aprendizagem dessa nova representação simbólica, promovida pela leitura e pela escrita, exige que o estudante ultrapasse a mera decodificação do alfabeto. Ele precisa ser envolvido em um processo de letramento, em que o desenvolvimento das "práticas sociais que envolvem a língua escrita" (SOARES, 2017, p.45) seja estimulado constantemente. Assim, caminhará de um estágio de domínio formal da escrita, proporcionado pela alfabetização, para o domínio das práticas sociais da escrita, o letramento. 
Promover o letramento é tarefa árdua, mas fundamental para o desenvolvimento linguístico dos aprendizes. Ele se situa dentro de um continuum, que vai desde domínios mais simples de escrita até aqueles mais complexos. A consciência do professor acerca da complexidade do Adriana aprendizado dessas novas habilidades comunicativas é um importanTavares te passo rumo a uma "articulação didática entre as práticas com a línMaurício Lessa gua materna" e "os saberes estruturais sobre essa língua" (GERHARDT, 2017 , p.1). Isso implica uma postura pedagógica dedicada a promover a Magda do tomada de consciência, por parte do aluno, de que a língua disponibiliza Nascimento aos seus usuários uma série de estruturas sintáticas, a serem utilizadas Rodrigues de acordo com os diferentes contextos comunicativos.

Kenedy (2016), ao discutir problemas relacionados aos índices de analfabetismo no Brasil, defende a existência de um bilinguismo universal, conforme Roeper (1999 apud KENEDY, 2016). Essa noção consiste na ideia de que os usuários de qualquer língua têm de utilizar diferentes conhecimentos gramaticais, que variam conforme os gêneros discursivos e as situações sociocomunicativas em que esses usuários estejam inseridos. Muitas dessas regras são incompatíveis entre si, e a criança em processo de aprendizado da escrita deverá se apropriar dessas diferentes informações gramaticais. Ela deverá adicionar ao seu conhecimento linguístico natural esses "novos itens lexicais, novas regras gramaticais e novos gêneros do discurso", tornando-se "fluente nas diversas modalidades socioculturais de seu idioma" (KENEDY, 2016, p. 196).

A proposta de bilinguismo universal retoma um interessante debate sobre o processo de aquisição ou aprendizagem de aspectos sintáticos. Há vasta literatura sobre as semelhanças e diferenças cognitivas entre o processo de aquisição da língua materna e o aprendizado de uma língua estrangeira como segunda língua (cf. PAIVA, 2017). Alguns desses estudos indicam que, quando a exposição à segunda língua ocorre em contexto instrucional, com base na análise linguística, o processo cognitivo é distinto daquele que se dá durante a aquisição de língua materna, de forma natural.

De acordo com Krashen (1982), a aquisição de uma segunda língua seria um processo natural, subconsciente, pessoal, tendo como foco a comunicação com base nas práticas de linguagem. Já a aprendizagem seria um processo artificial, consciente, tendo como foco a análise teórica da forma linguística com base na instrução formal. Em termos de resultado, aquisição estaria relacionada à "habilidade" do falante nas práticas lin- 
guísticas e aprendizagem, ao conhecimento do faltante sobre a língua. No entanto, o autor acredita que o nível de aprendizagem da língua pode auxiliar no desenvolvimento do processo de aquisição da segunda língua.

Pensando-se na aplicação desses conceitos de aquisição e aprendizagem para a escrita em língua materna, para a maior parte dos estudantes brasileiros, o contato com esse sistema de escrita formal e com a oralidade letrada se dará em contexto formal de aprendizado, no ambiente escolar. Logo, as condições de "aquisição" dessas modalidades se assemelham em muito ao aprendizado de uma segunda língua, dadas as grandes diferenças gramaticais observadas entre a escrita formal e o vernáculo brasileiro.

Em acordo com Krashen (1982), acreditamos que uma abordagem analítica da língua pode até amparar o aprendizado do paradigma gramatical presente nessas outras modalidades, desde que esteja ancorada A influência da oralidade na produção escrita de estudantes do ensino fundamental e servindo à potencialização das práticas de linguagem do estudante. Assim, parte da função do ensino de Língua Portuguesa seria promover o desenvolvimento de minigramáticas (ROEPER e AMARAL apud KENEDY, 2016, p. 199), em que "um número grande de itens lexicais e seus respectivos traços fonológicos, formais e semânticos sejam cultivados a tal ponto que desencadeiem processos gramaticais e discursivos inexistentes na gramática nuclear". Tal concepção estaria em acordo com a ideia de desenvolvimento metassintático, que se refere ao desenvolvimento da "habilidade de raciocinar conscientemente sobre os aspectos sintáticos da linguagem e de exercitar o controle intencional sobre a aplicação de regras gramaticais" (GOMBERT, 1992, p. 39).

A discussão da presente seção ilustra o nível de complexidade que envolve a pesquisa sobre o processo de ensino-aprendizagem de aspectos gramaticais associados à língua escrita. Com base nesse debate, retomando o primeiro objetivo deste artigo, de caracterizar sintaticamente a produção escrita dos estudantes: se essa produção demonstra refletir, de forma transparente, o paradigma gramatical da oralidade, a tomada de consciência sobre as diferenças sintáticas entre essas modalidades parece relevante para a potencialização de suas práticas de linguagem. Consequentemente, ao se debaterem as possíveis práticas pedagógicas para o desenvolvimento metassintático dos estudantes - segundo objetivo deste artigo -, deve-se assumir, como princípio subjacente, a intenção de se ampliar a estrita transposição dos usos sintáticos da prática oral para a escrita por uma prática ancorada na consciência dos traços específicos de cada modalidade, para além de uma visão de certo e errado. 


\section{Sintaxe da fala e da escrita}

Esta seção se propõe a apresentar as principais características sintáticas da fala e da escrita, sem a pretensão de esgotá-las. No entanto, antes, é importante destacarmos que não se defende uma mera observação

Adriana dicotômica de características sintáticas polares. Isso significa que, a Tavares Maurício Lessa

Magda do Nascimento

Rodrigues despeito de se delimitarem, neste artigo, determinadas características como típicas da escrita e outras como típicas da oralidade, assume-se como pressuposto que "as relações entre oralidade e escrita se dão num contínuo ou gradação perpassada pelos gêneros texuais", nos termos de Dionísio e Marcuschi (2007, p. 17). Cabe ao professor reconhecer e amparar os estudantes no processo de tomada de consciência de que tais mesclas são inerentes às práticas sociais.

Conforme se observa no gráfico 1 , neste contínuo ou gradação de gêneros entre os domínios da fala e da escrita, haveria, num extremo, gêneros textuais mais representativos da modalidade escrita, como o artigo científico (representando GE1), e, no extremo oposto, gêneros mais representativos da modalidade oral, como a conversação espontânea (representando GF1). Todavia, as estratégias de formulação textual que distinguem as estruturas sintáticas, progressão textual e seleções lexicais também podem ser correlacionadas no contínuo - destacam os autores -, como acontece numa palestra universitária ou numa carta pessoal.

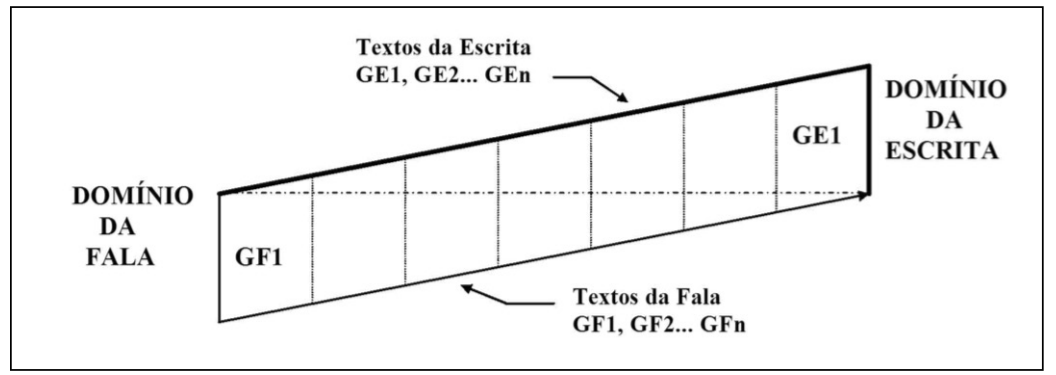

Gráfico 1 - o contínuo fala-escrita conforme Dionísio e Marcuschi (2007, p.61)

Reconhecendo a gradação dos gêneros nesse contínuo, este artigo se propõe a debater a estruturação sintática prototipicamente associada à fala em contraste àquela prototipicamente associada à escrita para, depois, discutir brevemente como os professores podem guiar os estudantes de Ensino Fundamental no processo de estruturação de seus textos escritos, dentro de um planejamento pedagógico de incentivo à prática linguística socialmente motivada. 


\subsection{Estruturação sintática na fala}

Ao tratarmos de estruturação sintática na fala, é importante esclarecer as características principais da língua falada. Conforme destacado por Marcuschi (2007), a língua falada tem características próprias que podem ser compartilhadas por textos escritos, sem descaracterizá-los como tal.

\section{A influência da oralidade na produção escrita de estudantes do ensino fundamental}

Contudo, não é o caso de se enfatizar demasiado essas características em contraste com outras, já que, por exemplo, os bate-papos na internet são um caso particular de produção discursiva que cumprem muitos desses requisitos, mas são linguagem escrita. $O$ mais importante na produção falada é a condição de produção sonora, processamento natural e em tempo real."

Nesta subseção, apresentam-se as principais características da organização sentencial na oralidade, a fim de, posteriormente, fundamentar a análise das marcas sintáticas de oralidade nas produções escritas de alunos do Ensino Fundamental. Tomam-se como base para essa explicação acerca das especificidades sintáticas do português brasileiro oral Castilho (2010), Bortoni-Ricardo (2016), Pontes (1986) e exemplos de autoria nossa.

A) Apagamento de termos oracionais - Nas interações espontâneas, o texto oral se ampara no contexto situacional. Assim, a ausência de elementos oracionais, na maioria das vezes, não acarreta problemas de compreensão, uma vez que o contexto comunicativo fornece essas pistas ao interlocutor. A sintaxe colaborativa, segundo Castilho (2010), permite que as estruturas sejam construídas no momento da interação. Para ilustrar, consideremos a situação em que dois colegas conversam sobre o atraso do ônibus. A situação torna desnecessária a lexicalização do tópico conversacional, o que possibilita a sentença sem preenchimento da posição de sujeito: “ $\Phi$ tá atrasado de novo, hein?”. 
B) Reativação de itens lexicais - A repetição de itens para fins de retomada é constante na oralidade, dada a impossibilidade de retomada desses elementos tal qual ocorre na escrita, em que o leitor pode retornar a alguma parte do texto caso algum problema de com-

Adriana preensão ocorra. Esse contexto imediato de enunciação exige coopeTavares ração entre os interlocutores, garantindo "seu mútuo envolvimento" Maurício Lessa (BORTONI-RICARDO, 2016, p.3). Para Marcuschi (2006 apud CASTILHO, 2010, p.234) são aspectos funcionais da repetição na oralidade: coesiMagda do vidade textual, facilidade na compreensão, organização tópica e conNascimento dução do argumento discursivo. Verificam-se esses aspectos no trecho Rodrigues a seguir, com a constante reativação do item lexical "preconceito": "Preconceito? Ah... esse negócio de preconceito... sei não... nunca fui vítima de preconceito não...".

\section{C) Ordenamento sintático do tipo tópico-comentário - Eunice} Pontes (1986) situa o português brasileiro falado na categoria de língua com tendência à estrutura tópico-comentário. Nessa estrutura, o ordenamento canônico $\mathrm{SN}+\mathrm{V}+\mathrm{SN}$ (ou seja, sujeito-predicado) é substituído pela estrutura $\mathrm{SN}(\mathrm{SN}+\mathrm{V}+\mathrm{SN})$ (ou seja, tópico-comentário), como se verifica no exemplo abaixo:

\section{O celular ele foi mais caro que o outro. SN [tópico] $(\mathrm{SN}+\mathrm{V}+\mathrm{SN})$ [comentário]}

Nesse novo ordenamento, a predicação principal se dá entre o primeiro sintagma (tópico) e o conjunto formado por $\mathrm{SN}+\mathrm{V}+\mathrm{SN}$ (comentário). Assim, em contraste com o sujeito na estrutura do tipo sujeito-predicado, o tópico na estrutura de tópico-comentário apresenta as seguintes características:

I) É sempre definido, em oposição ao sujeito, que pode ser indefinido.

II) Não apresenta relações selecionais com o verbo, nem é determinado por ele.

III) Tem um papel funcional, anunciando o tema do discurso.

IV) Não apresenta concordância com o verbo.

V) Ocupa a posição inicial na sentença.

VI) É dependente do discurso. 
D) Presença de itens fáticos - Itens fáticos são marcadores conversacionais, que aparecem como recursos utilizados para iniciar um turno, mantê-lo ou chamar a atenção dos interlocutores, como em: "Bom... eu sempre ia para Minas quando era criança, né? Aí acabei acostumando com a comida de lá.".

\section{A influência da oralidade na produção escrita de estudantes do ensino fundamental}

E) Marcação entoacional da fronteira sintática - Na oralidade, as coordenadas em relação ao início e ao fim dos turnos de fala são marcadas pelo falante através de sua entoação. Assim, estratégias de manutenção e assalto ao turno conversacional, como hesitações, pausas, variações nos tons melódicos das sentenças são utilizadas como recursos fundamentais à compreensão e desenvolvidos desde as fases iniciais de aquisição da fala. Essa variação no padrão entoacional é marcada por movimentos tônicos ascendentes e descentes, que funcionariam como recursos conversacionais, conforme se identifica no exemplo: "Na verdade... [movimento descendente] do que eu tava falando mesmo? [movimento ascendente] Ah... eu acho que o time do jeito que tá vai se dar mal...".

Tendo em vista a apresentação de cinco fenômenos linguísticos típicos da oralidade, acreditamos que sua análise poderá promover mudanças consideráveis na postura de todos os envolvidos no processo de aprendizagem. Ressalta-se, portanto, o papel decisivo da visão dos professores de língua materna em relação às características sintáticas prototípicas dessa modalidade, o que motivou o presente artigo.

Durante muito tempo, a escola combateu as manifestações linguísticas que não eram previstas pela norma gramatical. A partir da compreensão de que diferentes modalidades impõem diferentes modos de estruturação e certas particularidades, o olhar do professor em relação ao material escrito dos alunos também se altera. 0 reconhecimento das semelhanças e diferenças gramaticais típicas da escrita e da oralidade por parte do professor pode fornecer maior sustentação ao desenvolvimento do letramento dos estudantes, de modo a permitir uma tomada de consciência sobre como aspectos gramaticais e discursivos dialogam, a depender do grau de formalidade inerente ao registro. 


\subsection{Estruturação sintática na escrita}

A relação com o interlocutor e o planejamento linguístico são fatores determinantes das principais marcas distintivas entre fala e escrita. Enquanto, na fala, há a presença do interlocutor e o plane-

Adriana jamento é simultâneo ao momento de produção; na escrita, o diáTavares logo se estabelece na ausência de um interlocutor e o planejamenMaurício Lessa

Magda do Nascimento Rodrigues to se efetiva num momento anterior à execução (CASTILHO, 2010, p. 220). Por isso, conforme Marcuschi e Dionísio (2007) destacam, apesar de tanto a fala quanto a escrita contarem com planejamento - de níveis distintos -, a edição da fala, diferentemente da escrita, depende de correções, adendos e outras estratégias que são incorporadas ao texto.

Em outras palavras, essa ausência do interlocutor promove um outro tipo de postura do escritor. Ele precisa fazer suposições acerca de seu interlocutor, projetando expectativas. Isso significa que, na escrita, o interlocutor - embora ausente no momento da produção - também tem papel ativo durante o processo de produção, de modo que o interlocutor idealizado auxilia o processo construção do significado almejado pelo autor.

A atuação dos leitores sobre o material escrito, que se dá posteriormente ao momento da produção, também é citada por Bortoni-Ricardo (2016) como um traço importante da escrita. Os leitores teriam possibilidade de retomar, avançar ou recuar no texto, o que acaba por favorecer a compreensão de estruturas sintáticas mais complexas. $\mathrm{Na}$ oralidade, essas possíveis dificuldades podem ser sanadas a partir de paráfrases e repetições, como visto na seção 2 .

Portanto, há uma relação de coautoria entre interlocutores nas duas modalidades, todavia os momentos de produção e recepção não são simultâneos na escrita. Nesse sentido, Castilho (2010) afirma que o texto escrito "dissimula o processamento linguístico", originando, por exemplo, os seguintes produtos:

A) Parágrafo: unidade da língua escrita, em que deve ocorrer a presença de um tópico que não pode ser omitido, além de uma ligação entre o que já foi apresentado e a informação nova a partir de conectivos e termos referenciais que estabeleçam essas relações de ordem sintática e semântica. 
B) Sintaxe específica: estruturas sintáticas com tendência ao processo de subordinação, ausência de anacolutos e truncamentos. Predominam as construções de sujeito-predicado e as sentenças declarativas, com o uso mais abundante de voz passiva e uma maior frequência de expressões fóricas, como "conforme o que foi dito anteriormente".

\section{A influência da oralidade na produção escrita de estudantes do ensino fundamental}

Essa caracterização de fala e de escrita acaba por polarizar essas modalidades, mantendo a supremacia de uma sobre a outra. $\mathrm{O}$ autor sugere, assim, que elas sejam consideradas a partir de um continuum, "indo da oralidade para a escrituralidade, percorrendo diferentes graus de formalidade" (CASTILHO, 2010, p. 222).

\section{Estruturação sintática na escrita de alunos do Ensino Fundamental}

Todo professor já ouviu críticas marcadas de preconceito linguístico quanto aos alunos não "saberem escrever" e apresentarem "problemas graves de redação". Normalmente, essas falas são acompanhadas de uma visão nebulosa, em que não se é capaz de identificar que ditas "dificuldades" seriam essas. Neste artigo, que tem como objetivo caracterizar sintaticamente a produção dos estudantes, analisamos alguns casos de produções que poderiam ser classificadas como "problemáticas" por um professor que não tenha consciência das principais características do paradigma sintático do português brasileiro oral. Neste artigo, esperamos romper com esse tipo de visão estigmatizada a partir da identificação e análise de estruturas sintáticas que representam a transposição da fala para a escrita. 
Os exemplos que utilizamos para ilustrar essas principais transposições são oriundos de um levantamento realizado a partir de produções escritas de alunos do sétimo ano do Ensino Fundamental ${ }^{1}$. Esses textos são fruto de uma solicitação da professora para que os alunos es-

Adriana crevessem um pequeno texto acerca da greve dos caminhoneiros, ocorTavares rida em maio de $2018 \mathrm{em}$ todo o Brasil, que havia comovido a turma. $\mathrm{O}$ Maurício Lessa

Magda do Nascimento

Rodrigues texto deveria ter caráter dissertativo-argumentativo, sendo organizado da seguinte maneira: um parágrafo inicial, em que eles trariam informações sobre o evento, e um parágrafo em que eles deveriam expor suas opiniões acerca do movimento, apontando e compartilhando com os colegas as consequências percebidas em seus cotidianos. A proposta de produção textual permitiu que os alunos manifestassem suas opiniões a respeito de um tema que os afetou diretamente. Além disso, teve uma outra finalidade: foi tomado como objeto de ensino/aprendizagem, já que permitiu que um mapeamento das características sintáticas mais recorrentes nos textos dos alunos fosse realizado.

Os exemplos selecionados são apresentados no quadro I, organizados a partir das principais marcas de oralidade identificadas, já apresentadas na seção 2 deste artigo.

1 Conforme o inciso VII do Parágrafo Único do Art. 10 da Resolução CNS 510/2016, não são registradas nem avaliadas pelo sistema CEP/CONEP pesquisas que objetivam o aprofundamento teórico de situações que emergem espontânea e contingencialmente na prática profissional, desde que não revelem dados que possam identificar o sujeito. 


\section{Quadro I: Marcas sintáticas de oralidade na produção escrita de alunos do Ensino Fundamental}

\begin{tabular}{|c|c|}
\hline Marca de oralidade & Exemplo \\
\hline \multirow{3}{*}{$\begin{array}{l}\text { Apagamento de } \\
\text { termos oracionais }\end{array}$} & $\begin{array}{l}\text { (1) E aí aconteceu que os caminhoneiros ficaram parados, em } \\
\text { todas as estradas do Brasil por causa do aumento do óleo diesel, } \\
\text { falta de alimentos nos mercados e sem gasolina. }\end{array}$ \\
\hline & $\begin{array}{l}\text { (2) A greve dos caminhoneiros começou no dia } 14 \text { de maio, termi- } \\
\text { nou no dia } 28 \text { de maio, ficaram sem aula nas escolas, faltaram } \\
\text { alimentos nos mercados. }\end{array}$ \\
\hline & $\begin{array}{l}\text { (3) Na minha opinião, os caminhoneiros estão certos, porque eles } \\
\text { estavam lutando por um direito deles e o único jeito deles tentar } \\
\text { abaixar o preço foi fazendo a paralisação, muitos criticaram, } \\
\text { mas também não vê o lado dos caminhoneiros. }\end{array}$ \\
\hline \multirow[b]{2}{*}{$\begin{array}{l}\text { Reativação de itens } \\
\text { lexicais }\end{array}$} & $\begin{array}{l}\text { (4) Muitas pessoas sofreram com a greve, muitas pessoas tive- } \\
\text { ram que armazenar comida em suas residências. }\end{array}$ \\
\hline & $\begin{array}{l}\text { (5) Os caminhoneiros se juntaram para fazer uma greve sobre o } \\
\text { valor do diesel e do pedágio. A greve foi pelo dia } 14 \text { a } 26 \text { de maio, } \\
\text { a greve ocorreu pelo Brasil inteiro. As consequências da greve foi } \\
\text { a falta de alimentos nos supermercados e nas escolas, a falta de } \\
\text { remédios nas farmácias e o gás de cozinha. }\end{array}$ \\
\hline \multirow{2}{*}{$\begin{array}{l}\text { Ordenamento } \\
\text { sintático do tipo } \\
\text { tópico-comentário }\end{array}$} & (6) A greve eu acho que não vale a pena. \\
\hline & (7) Quando ocorreu a greve, ela ocorreu no dia 14 a 28 de maio. \\
\hline \multirow{2}{*}{$\begin{array}{l}\text { Ocorrência de itens } \\
\text { fáticos }\end{array}$} & $\begin{array}{l}\text { (8) Bom a greve ocorreu no dia } 14 \text { de maio por causa do aumento } \\
\text { do preço dos combustíveis. }\end{array}$ \\
\hline & $\begin{array}{l}\text { (9) Os caminhoneiros bloquearam as estradas e aí os mercados } \\
\text { deixaram de receber mercadorias e as escolas ficaram sem aula. }\end{array}$ \\
\hline $\begin{array}{l}\text { Não marcação de } \\
\text { fronteira sintática }\end{array}$ & $\begin{array}{l}\text { (10) A greve teve início no dia } 14 \text { de maio foi em todo o Brasil } \\
\text { começou com a falta de comida, gasolina e água e também teve } \\
\text { aumento do diesel as escolas não tem aula o governo estavam } \\
\text { tentando tudo para que a greve tivesse fim e queria fazer voltar } \\
\text { a comida, gasolina, etc Hospitais estavam sem remédio e cirurgia } \\
\text { marcadas para outros dias comidas entregadas de skate e bike } \\
\text { pois não tinha gasolina. }\end{array}$ \\
\hline
\end{tabular}

Quanto aos casos de apagamento de termos, o exemplo (1) ilustra uma estrutura sintática típica da oralidade que pode gerar dificuldade de compreensão ao leitor. Pelo contexto sintático, o leitor é induzido a pensar que "o aumento de óleo diesel, falta de alimentos nos mercados e sem gasolina" representam fatos causadores da greve, devido ao uso da vírgula, necessariamente interpretada como vírgula enumerativa pela ausência de um outro núcleo verbal predicador. No entanto, semanticamente, a estrutura nominal que faz referência à falta de ali- 
Adriana

Tavares

Maurício Lessa

Magda do

Nascimento

Rodrigues

mentos e de gasolina representa o resultado de toda a situação descrita anteriormente no período. Observa-se, portanto, que não se trata de um caso de elipse verbal, sintaticamente adequada ao registro escrito. Todavia, na oralidade, o trecho em destaque pode ser utilizado de forma elíptica, como um acarretamento do fato de os caminhoneiros terem parado, vinculado de forma sintaticamente frouxa - compatível com a oralidade - à estrutura resultativa da oração principal "e aí aconteceu".

Além do núcleo verbal, pode ocorrer o apagamento dos complementos verbais, denominados por Castilho (2010) como argumentos externos (sujeito) e argumentos internos (objetos). o exemplo (2) ilustra o apagamento de argumento externo, também em uma estrutura com carga semântica resultativa, que propicia esse apagamento do sujeito, dada a baixa agentividade da situação. Por fim, o exemplo (3) ilustra o apagamento de argumento interno².

Quanto à reativação de itens lexicais, é importante esclarecer que, na escrita, essa retomada gera a coesão textual, normalmente, a partir de pronomes e do uso de novos sintagmas nominais de mesmo valor semântico. Na fala, ocorre o mesmo processo de retomada, porém observa-se uma frequência maior de repetições do mesmo termo, que representa um aspecto facilitador da compreensão na oralidade. No entanto, na escrita, esse tipo de reativação a partir do mesmo item lexical tem efeito reverso, tornando a leitura mais custosa cognitivamente, como se pode verificar pelos exemplos (4) e (5).

Pelos exemplos (6) e (7), ilustramos o ordenamento sintático do tipo tópico-comentário. Em (7), observa-se que o sujeito da oração subordinada assume posição inicial da sentença, como tópico discursivo. Em (8), a estrutura de tópico-comentário ocorre em contexto de reformulação da proposição, comum na oralidade. Observa-se que ambas as orações do período cumprem o mesmo propósito de informar tempo. No entanto, o trecho que antecede "a greve" é desconsiderado pelo escritor, que parece retomar o tópico discursivo gerando outra sentença comentário.

Nos exemplos (8) e (9), os itens fáticos "bom" e "e aî" marcam momentos distintos do discurso, em tom de conversação: o início da colocação e a continuidade da narrativa, respectivamente. Na escrita, o

2 Embora o apagamento do objeto direto seja listado como estrutura típica da oralidade, é importante destacar que esse tipo de fenômeno já ocorre tanto na fala quanto na escrita letrada do português brasileiro de forma não estigmatizada (cf. FREIRE, 2005). 
primeiro marcador poderia ter sido simplesmente omitido e o segundo, substituído pela marcação de fronteira sintática e inclusão de um conectivo que indicasse a ideia de consequência.

Finalmente, o exemplo (10) ilustra a ausência de marcação de fronteiras sintáticas pelo estudante. É interessante destacar que a oralidade possui sua organização lógica para marcação entoacional, conforme apresentamos na seção 2. Dentre as diferentes marcações entoacionais, ocorre também a marcação de fronteiras sintáticas. Ou seja, não há uma relação biunívoca entre pontuação (guiada por critérios sintáticos) e marcação entoacional (guiada por critérios conversacionais). Acreditamos que a escolha do estudante por não marcar nenhuma dessas fronteiras pelos sinais de pontuação seja fruto da confusão gerada pelo fato de esse não ser o único critério adotado na fala para marcação entoacional.

\section{A influência da oralidade na produção escrita de estudantes do ensino fundamental}

\section{0 professor e o desenvolvimento metassintático}

Após a ilustração e análise das transferências realizadas pelos alunos, podemos dizer que, os alunos em fase inicial de aprendizagem da escrita transferem para a escrita as características fonológicas, lexicais, gramaticais, sintáticas e discursivas presentes na oralidade, conforme Kato (1986 apud KENEDY, 2016, p. 201). Em outras palavras, os processos cognitivos que os estudantes já dominam, condizentes com a sintaxe das práticas orais, são replicados em suas práticas de escrita formal. Essa ideia dialoga com o seguinte debate acerca da relação dos professores com a oralidade:

\footnotetext{
Muito frequentemente, tudo que é novo na escrita é considerado pelos professores como erro, e porque há tão poucos estudos do português oral, eles não sabem porque os alunos tendem a usar alguns tipos de Ss em vez de outras. A importância, então, da descrição das estruturas da língua oral é evidente, já que se os próprios professores não conhecem as estruturas da língua oral, eles não podem compreender muitas das dificuldades que seus alunos têm no processo de aprendizagem da escrita (PONTES, 1980, p. 85).
}

Isso evidencia duas grandes necessidades primárias: a primeira refere-se ao estudo da oralidade em sala de aula. É bastante limitado o espaço dado à aprendizagem e ao aprimoramento dessa modalidade durante as aulas de Língua Portuguesa. Os estudos sociolinguísticos, que 
tanto têm contribuído para o desenvolvimento de uma nova cultura escolar a respeito das manifestações linguísticas, precisam ser transpostos para o ensino. A segunda refere-se à adoção de posturas metodológicas que promovam uma reflexão acerca da ocorrência de certas esAdriana truturas orais em textos escritos. Logo, o reconhecimento dos motivos Tavares que levam os alunos a utilizarem certas estruturas deve ser o ponto de Maurício Lessa

Magda do partida para a elaboração de estratégias de ensino de escrita.

Sendo assim, o primeiro passo é que o professor seja capaz Nascimento Rodrigues de reconhecer as características sintáticas da língua oral e incentive essa mesma tomada de consciência por parte do estudante. Além disso, pensando na prática pedagógica do professor, como tratamos de processos cognitivos cristalizados, é imprescindível que o professor também tenha consciência de que a expansão desses processos cognitivos vinculados à prática da escrita depende de paulatina mediação pedagógica em um percurso escolar que considere como objeto de ensino-aprendizagem a escrita não como produto, mas sim como processo. Portanto, para o desenvolvimento metassintático, essa mediação assumiria como objetivo de aprendizagem a tomada de consciência das diferentes possibilidades de organização sintática das ideias na oralidade e na escrita a partir de sua prática para o desenvolvimento dessas minigramáticas, tal qual um processo de aquisição de segunda língua.

Conforme debatemos na seção 1, quando tratamos de aquisição, tratamos de foco em prática comunicativa. Entende-se que a intervenção do docente nessa direção será determinante para a potencialização das formas de expressão linguística dos alunos. Interessa-nos, portanto, saber: como realizar essa intervenção?

Reconhece-se que o mero apontamento e correção automatizada do "erro", no nível sintático, não parece indicar melhorias nos textos de alunos cuja experiência com a escrita ainda é restrita. Nessa direção, Gerhardt (2016, p. 43) defende a adoção de uma perspectiva metalinguística de observação e ensino da língua, cujo foco recaia não sobre os componentes linguísticos usados metalinguisticamente, mas sobre o comportamento e a relação das pessoas com a sua experiência linguística. Não se trata da análise dos elementos linguísticos: a atividade metalinguística vai além do conhecimento sobre o que se está dizendo ou escrevendo, ela representa uma avaliação consciente do texto que se produz. 
Numa perspectiva metalinguística (logo, metacognitivista), os ditos "erros" e "acertos" têm ambos sua relevância no desenvolvimento metalinguístico do estudante e, consequentemente, no processo pedagógico a ser mediado pelo professor. A partir do foco nessas diferentes estruturas sintáticas, uma vez detectados os diferentes paradigmas sintáticos nas modalidades oral e escrita, a tomada de consciência abrange não só a escrita, mas a leitura e as práticas de oralidade.

Como caminho pedagógico em busca dessa tomada de consciência, Myhill, Jones e Wilson (2016) apontam como estratégia metalinguística a gestão de conversas sobre a escrita em sala de aula. Os autores propõem interações dialógicas professor-aluno para a construção de uma compreensão metalinguística, com pouca fala do professor e foco de análise claro. 0 trabalho em sala demandaria, assim, a participação

A influência da oralidade na produção escrita de estudantes do ensino fundamental ativa e orientada dos alunos, que devem elaborar perguntas, explicar suas escolhas linguísticas e comentar as ideias uns dos outros (MYHILL, JONES e WILSON, 2016, p. 4). Defendemos, aqui, a adoção de um ensino dialógico nesses moldes para que se explore a composição sintática das produções textuais dos estudantes.

Com a finalidade de demonstrar de que forma os diálogos em sala podem interferir positivamente sobre o processo de escrita dos alunos, defendemos, neste artigo, como prática pedagógica possível para o desenvolvimento metassintático, que, como parte central da aula, os alunos sejam levados a: (1) refletir sobre a escrita a partir de suas próprias produções, com foco em algum aspecto orientado pelo professor; (2) interagir entre pares para a análise de determinados textos e resolução de algumas questões levantadas pelo grupo; (3) apresentar sugestões de reescrita em que sejam observadas as formas de estruturação típicas da escrita em contraste com as da fala.

\section{Conversas metassintáticas: um breve relato de experiência}

A fim de ilustrar a proposta apresentada na seção anterior, relatamos uma experiência pedagógica vivida por uma das autoras deste artigo. A partir dos três principios norteadores apresentados ao fim da seção 4, elaborou-se uma aula com foco em conversas metassintáticas sobre a prática escrita dos estudantes. Logo, o objetivo era a tomada de consciência sobre as escolhas sintáticas feitas por um aluno no momento da formulação de um parágrafo, com foco, especificamente, na marcação de fronteiras sintáticas. 0 texto selecio- 
nado para análise e intervenção era uma produção real de aluno, anônima, e trazia construções em que a ausência da marcação de fronteiras sintáticas era bastante evidente. Além disso, trazia um modo de organização de ideias bastante comum na fala, com truncamento de informações que podem ser

Adriana

Tavares

Maurício Lessa

Magda do

Nascimento

Rodrigues

480

(11) No começo da greve em 14 de maio quando começou essa greve em todo o Brasil, com essa greve muitos comércios se fecharam por causa do aumento da gasolina os caminhões ficaram parado na pista atrapalhando os outros não deixando passar e os alimentos não chegaram aos comércios e mercados.

Como se propõe uma aula dialógica, ao serem perguntados sobre a impressão que a leitura do trecho causou, os alunos apresentaram, inicialmente, uma reação de incômodo em relação àquela estruturação sintática. Caracterizaram o texto como "repetitivo, confuso", além de tecerem comentários que revelam o valor social que a escrita possui, pois o autor (anônimo) do parágrafo foi intelectualmente julgado a partir do que escreveu, permitindo ao professor um debate mais amplo acerca de variação e preconceito linguístico.

Após esse momento inicial, na segunda etapa da aula, os alunos foram progressivamente instigados, de forma dialógica, a: (a) definir o tema do parágrafo e reconhecer a estratégia utilizada pelo autor para o desenvolvimento desse tema; (b) reconhecer o objetivo das repetições presentes na parte inicial do texto e (c) identificar se o autor havia se utilizado da estrutura sujeito-predicado. Os alunos concluíram que a parte inicial do parágrafo tinha um valor circunstancial, situando temporalmente o evento, e que, embora as informações estivessem "bagunçadas", o autor havia utilizado a estrutura sujeito-predicado. É interessante destacar que, ao longo dessas conversas metassintáticas, a ausência de pontuação foi indicada por eles como o grande problema do parágrafo. Essa percepção partiu naturalmente deles, sem que fosse necessária qualquer intervenção da professora.

Na terceira etapa da aula, uma aluna foi convidada, então, a ir ao quadro e marcar o início e o fim das sentenças. A turma participou desse momento, apresentando sugestões à colega. Perguntada ao final da atividade sobre o critério utilizado, a aluna afirmou ter se baseado em sua experiência com a leitura para pontuar o trecho, ou seja, ela não associou esse exercício na prática escrita a conhecimentos gramaticais aprendidos sobre "regras" de pontuação. 
Ao final, os alunos foram convidados a reescrever os parágrafos, observando as questões metalinguísticas levantadas durante o diálogo com a professora. Selecionamos dois parágrafos, a título de exemplificação, apresentados em (12) e (13):

(12) Em 14 de maio, começou uma greve em todo o Brasil. Com isso, muitos comércios se fecharam por conta do aumento do combustível e a parada dos caminhoneiros, que atrapalharam a passagem dos alimentos, não chegando aos mercados e comércios.

(13) A greve começou em 14 de maio em todo o Brasil. Essa paralisação ocorreu por causa do aumento do óleo diesel. Como forma de reinvidicação de tal medida, os caminhoneiros ficaram parados na pista, atrapalhando os outros e não deixando passar mercadorias para as lojas e mercados.

Uma análise da reescrita apresentada nesse dois exemplos permite algumas constatações. Em (12), houve a preocupação do autor em fazer uso dos sinais de pontuação no interior do parágrafo, separando a expressão adverbial temporal presente no início por meio de vírgula. Em (13), também se verifica a adoção de pontuação no interior do parágrafo, estruturando três sentenças mais curtas. Em ambos, os alunos recorreram a elementos coesivos, como pronomes, para fazer a conexão entre as partes do texto e reorganizaram as ideias de modo a destacar a relação de causa e consequência entre os fatos.

\section{Considerações Finais}

Este artigo buscou caracterizar sintaticamente a influência da oralidade na produção escrita de estudantes do Ensino Fundamental. Para tanto, apresentamos os processos cognitivos relacionados à sintaxe e à escrita; caracterizamos sintaticamente a língua oral e a língua escrita e, finalmente, ilustramos manifestações das principais marcas sintáticas de oralidade na sua produção escrita, quais sejam: apagamento de termos oracionais, reativação de itens lexicais, ordenamento sintático do tipo tópico-comentário, ocorrência de itens fáticos e não marcação da fronteira sintática.

Com isso, demonstramos a organização sintática típica da oralidade que, muitas vezes, manifesta-se na escrita, a partir de uma transferência do conhecimento que os alunos têm de uma modalidade para a outra. Considerando os processos cognitivos que embasam a produção oral dos alunos, argumentamos em favor de práticas pedagógicas que tenham como foco a prática escrita enquanto processo. Especificamente, defendemos a intenção pedagógica de mediar o processo do aluno de 
tomar consciência das estruturas sentenciais típicas não só da escrita, mas também da oralidade, já que é por meio dessa modalidade que as pessoas têm suas primeiras experiências comunicativas.

O professor, atento a essas particularidades, pode elaborar es-

Adriana tratégias que promovam o aprimoramento dos textos escritos. É imporTavares tante que a prática pedagógica adotada pelo professor propicie a toma-

Maurício Lessa

Magda do

Nascimento

Rodrigues da de consciência pelos alunos de que oralidade e escrita apresentam determinadas características diferenciadas de estruturação sintática, adequadas a cada situação comunicativa, de modo a promover o aprimoramento gradual das práticas nas duas modalidades.

Tal desenvolvimento metassintático pode ser facilitado a partir da adoção de estratégias pedagógicas metacognitivistas, em que os alunos sejam inseridos em ambientes de discussões sobre os recursos linguísticos utilizados por eles e as opções disponibilizadas pela língua que podem levá-los a um progresso em suas práticas comunicativas, seja por meio da fala, seja por meio da escrita. A fim de ilustrar uma possível prática pedagógica, relatamos uma experiência de aula com base em conversas metassintáticas, partindo das produções escritas dos próprios alunos. Acreditamos que o compartilhamento desse tipo de prática promova novas concepções e novas posturas em relação ao ensino de Língua Portuguesa com vistas à potencialização das práticas linguísticas dos estudantes.

\section{Referências}

BAGNO, Marcos. Nada na língua é por acaso: por uma pedagogia da variação linguística. $3^{\text {a }}$ ed. São Paulo: Parábola Editorial, 2009.

BORTONI-RICARDO, Stella Maris; GONDIM, Márcia Regina; BENÍCIO, Miliane Nogueira Magalhães. $O$ papel da oralidade na aquisição da cultura letrada. In: HEINIG, Otília Lizete; FRONZA, Cátia de Azevedo (orgs.). Diálogos entre Linguística e Educação. Blumenau: Edifurb, 2010, p. 187-205.

BORTONI-RICARDO, Stella Maris et al. Por que a escola não ensina gramática assim?. São Paulo: Parábola Editorial, 2016.

CASTILHO, Ataliba de. Nova Gramática do Português Brasileiro. São Paulo: Contexto, 2010. 
DIONÍSIO, Angela; MARCUSCHI, Luiz Antônio. Fala e Escrita. Belo Horizonte: Autêntica, 2007.

FREIRE, Gilson. Acusativo e dativo anafóricos de $3^{\text {a }}$ pessoa na escrita brasileira e lusitana. Revista da ABRALIN, v.10, n.1, p. 11-32, jan./ jun. 2011.

GERHARDT, Ana Flávia Lopes Magela. Ensino de Gramática e desenvolvimento metalinguístico: teorias, reflexões e exercícios. São Paulo: Pontes, 2016.

A influência da oralidade na produção escrita de estudantes do ensino fundamental . O Letramento Linguístico e o Ensino de Gramática da Língua Portuguesa no Brasil. Diadorim. Rio de Janeiro, Revista 19, v. 2, p. 48-75, Jul-Dez. 2017.

GOMBERT, Jean Émile. Metalinguistic Development. Tradução de Tim Pownall. Exeter: Harvester Wheatsheaf, 1992.

KENEDY, Eduardo. O status da norma culta na língua-I dos brasileiros e seu respectivo tratamento na escola: algumas contribuições de estudos formalistas à educação. In: GUESSER, Simone (org.). Linguística: pesquisa e ensino. Boa Vista: EDUFRR, 2016, p. 185-208.

$\mathrm{KOCH}$, Ingedore G. Villaça. Desvendando os segredos do texto. São Paulo: Cortez Editora, 2002.

KRASHEN, Stephen. Principles and Practice in Second Language Acquisition. California: University of Southern California, 1982.

MARCUSCHI, Luiz Antônio. A oralidade no contexto dos usos lingüísticos: caracterizando a fala. In: DIONÍSIO, Angela; MARCUSCHI, Luiz Antônio. Fala e Escrita. Belo Horizonte: Autêntica, 2007.

MYHILL, Debra; JONES, Susan; WILSON, Anthony. Writing Conversations: Fostering Metalinguistic Discussion About Writing. Research Papers in Education, 31(1), 2016, 23-44. 
PAIVA, Vera Lúcia Menezes de Oliveira e Paiva. Aquisição de segunda língua. $2^{\mathrm{a}}$ ed. São Paulo: Parábola Editorial, 2014.

PONTES, Eunice Souza Lima. o tópico no português do Brasil.

Adriana Campinas: Pontes, 1987.

Tavares

Maurício Lessa

SOARES, Magda. Alfabetização e letramento. $7^{\text {a }}$ ed. São Paulo: Contexto, 2017.

Magda do

Nascimento

VIEIRA, Silvia. Gramática, Variação e Ensino: diagnose e pro-

Rodrigues postas pedagógicas. São Paulo : Blucher, 2018. 